\title{
Enhanced Photocatalytic Degradation of Rhodamine B Using C/Fe Co-Doped Titanium Dioxide Coated on Activated Carbon
}

\author{
Thuy Le Thi Thanh $\mathbb{D}^{1},{ }^{1}$ Lan Nguyen Thi, ${ }^{1}$ Trinh Tran Dinh $\mathbb{D},{ }^{2,3}$ and Noi Nguyen Van ${ }^{2,3}$ \\ ${ }^{1}$ Department of Chemistry, Faculty of Science, Qui Nhon University, No. 170 An Duong Vuong Street, Qui Nhon, Vietnam \\ ${ }^{2}$ Faculty of Chemistry, VNU-University of Science, No. 19 Le Thanh Tong Street, Hanoi, Vietnam \\ ${ }^{3}$ VNU Key Laboratory of Advanced Materials for Green Growth, No. 334 Nguyen Trai Street, Hanoi, Vietnam
}

Correspondence should be addressed to Thuy Le Thi Thanh; lethithanhthuy@qnu.edu.vn and Trinh Tran Dinh; trinhtd@ vnu.edu.vn

Received 15 March 2019; Accepted 21 May 2019; Published 23 June 2019

Academic Editor: Mallikarjuna N. Nadagouda

Copyright (c) 2019 Thuy Le Thi Thanh et al. This is an open access article distributed under the Creative Commons Attribution License, which permits unrestricted use, distribution, and reproduction in any medium, provided the original work is properly cited.

\begin{abstract}
Carbon and iron co-doped titanium dioxide catalyst coated on activated carbon $\left(\mathrm{Fe}-\mathrm{C}-\mathrm{TiO}_{2} / \mathrm{AC}\right)$ was successfully synthesized using the sol-gel method, followed by hydrothermal treatment. Commercial activated carbon was treated by $\mathrm{HNO}_{3}$ prior to being coated by the as-synthesized catalyst. The composite was characterized by XPS, XRD, UV-Vis spectrophotometry, IR, TEM, HRTEM, and BET. The performance of the supported catalysts was evaluated in the degradation of rhodamine $\mathrm{B}(\mathrm{RhB})$ in the solution under visible-light irradiation. The results showed that, with the appropriate amount of activated carbon, prepared $\mathrm{Fe}-\mathrm{C}-\mathrm{TiO}{ }_{2} / \mathrm{AC}$ catalysts exhibited higher catalytic activities and $\mathrm{Fe}-\mathrm{C}-\mathrm{TiO}_{2} / \mathrm{AC}$ system showed the best performance. The photocatalytic degradation efficiency of $\mathrm{Fe}-\mathrm{C}-\mathrm{TiO}_{2} / \mathrm{AC}$ was enhanced due to the synergistic effect between $\mathrm{AC}$ (adsorption effect) and $\mathrm{Fe}-\mathrm{C}$ - $\mathrm{TiO}{ }_{2}$ (photocatalysis effect). This facilitated the photocatalytic degradation of $\mathrm{RhB}$ by $\mathrm{Fe}-\mathrm{C}-\mathrm{TiO}_{2}$.
\end{abstract}

\section{Introduction}

$\mathrm{TiO}_{2}$ photocatalyst has been widely used in the wastewater treatment and other environmental remediation because of its high efficiency, nontoxicity, propitious recycle ability, and low cost. Besides, the final products of the photocatalysis in the advanced oxidation process are $\mathrm{CO}_{2}, \mathrm{H}_{2} \mathrm{O}$, inorganic ions, and minerals that usually have insignificant impacts on environments $[1,2]$. However, the application of $\mathrm{TiO}_{2}$ is limited because the $\mathrm{TiO}_{2}$ with band gap $\sim 3.2 \mathrm{eV}$ is only activated under UV radiation and it is difficult to recycle. Therefore, modification of catalyst is crucial to enhance its photocatalytic activity. To present, catalytic efficiency of $\mathrm{TiO}_{2}$ was significantly improved by being doped with metals such as $\mathrm{V}, \mathrm{Cr}, \mathrm{W}$, and $\mathrm{Fe}$ or with metal oxides like $\mathrm{ZnO}$, $\mathrm{CuO}$, and so on for expanding the absorption edge to the visible region [3-6]. Among these metals, $\mathrm{TiO}_{2}$ doped with $\mathrm{Fe}$ is in progress because $\mathrm{Fe}$ can replace the positions of $\mathrm{Ti}^{4+}$ in the crystalline, reducing the band gap energy, which is conducive to the activation in the visible light $[3,4,7]$.
Moreover, $\mathrm{Fe}$ ions act as traps to incarcerate electrons and hinder the recombination of electron/hole pairs, resulting in the increase in catalysts' performance. In addition, the addition of some nonmetal elements such as N, C, S, P, and halogens into $\mathrm{TiO}_{2}$ structure can also narrow the band gap of $\mathrm{TiO}_{2}$, reinforcing the photocatalytic activity of the catalyst $[2,8]$. Some research reported that transition metals/(N, C, S) co-doped into $\mathrm{TiO}_{2}$ would greatly facilitate the photocatalytic performance of the corresponding catalysts under visible irradiation conditions, which was attributed to the synergistic effects between the doped $\mathrm{C}$ and $\mathrm{N}$ atoms and lower band gap energy $[1,3] . \mathrm{TiO}_{2}$-based photocatalysts are usually employed either as slurry or on support. In slurry condition, a big challenge lies in the separation and recovery of the small-sized particles after treatment of pollutants, which limits the application of the photocatalyst in real conditions. The utilization of support immobilization such as glass fibers, glass beads, or steel has also been employed. However, they have issue due to adhesion force between the photocatalyst surface and the support [9]. Recently, there are increasing interests in 
a synergetic approach. Different materials are usually designed to provide a high surface area to support the catalyst $[8,10]$. These materials share some common characteristics: binding to the catalyst, nondestroying catalyst, high surface area, and high affinity to the adsorption of pollutant molecules [10]. Activated carbon is one of the cost-effective synergist with not only clutching the photo-agents and free radicals (HO) but also adsorbing pollutant molecules on the photochemical centers of the catalyst apart from its mechanical stability [10]. There are surprisingly quite a few papers using this method, and there is no published work on $\mathrm{C} / \mathrm{Fe}$ codoped titanium dioxide coated on activated carbon that is reported in this manuscript. Hence, in the present work, $\mathrm{TiO}_{2}$ co-doped iron and carbon coated on activated carbon that was treated by $\mathrm{HNO}_{3}$ was prepared by sol-gel followed by solvothermal method. The characterization of the catalyst was conducted by X-ray photoelectron spectroscopy (XPS), X-ray diffraction (XRD), infrared spectroscopy (IR), transmission electron microscopy (TEM), high-resolution transmission electron microscopy (HR-TEM), ultraviolet-visible (UV-Vis) spectroscopy, and Brunauer-Emmett-Teller (BET) surface area measurement. The catalytic activity of the catalyst was examined by the degradation of $\mathrm{RhB}$ dye.

\section{Experimental}

\subsection{Catalyst Preparation}

2.1.1. Chemicals. TIOT (tetraisopropyl orthotitanate 98\%), nitric acid $\left(\mathrm{HNO}_{3} 68 \%\right)$, ethyl alcohol $\left(\mathrm{C}_{2} \mathrm{H}_{5} \mathrm{OH} 99.7 \%\right)$, iron (III) nitrate $\left(\mathrm{Fe}\left(\mathrm{NO}_{3}\right)_{3} \cdot 9 \mathrm{H}_{2} \mathrm{O}\right.$ pure), and rhodamine $\mathrm{B}$ $\left(\mathrm{C}_{28} \mathrm{H}_{31} \mathrm{ClN}_{2} \mathrm{O}_{3}\right)$ were purchased from Sigma-Aldrich. Activated carbon Tra Bac (AC-particle sizes from $0.075 \mathrm{~mm}$ to $4.75 \mathrm{~mm}$, surface area BET $928 \mathrm{~m}^{2} / \mathrm{g}$ ) was obtained with the aid of a TriStar 3000 V6.07 A.

\subsubsection{Preparation of $\mathrm{Fe}-\mathrm{C}-\mathrm{TiO}_{2}$ Coated on Activated Carbon Pretreated by $\mathrm{HNO}_{3}\left(\mathrm{Fe}-\mathrm{C}-\mathrm{TiO}_{2} / \mathrm{AC}\right)$}

(i) Treatment of carbon with $\mathrm{HNO}_{3}$ : The coal is ground to a fine powder $0.16 \mathrm{~mm}$ before being washed with water and boiled for 2 hours to eliminate gases such as $\mathrm{O}_{2}$, $\mathrm{CO}_{2}$, and $\mathrm{SO}_{2}$. Next, extracted carbon was immersed into $\mathrm{HNO}_{3} 12 \mathrm{M}$ and stirred for 3 hours at room temperature and then soaked for 24 hours. Finally, activated carbon (AC) was washed several times with distilled water and then dried for 3 hours at $100^{\circ} \mathrm{C}$.

(ii) Preparation of Fe-C- $\mathrm{TiO}_{2} / \mathrm{AC}: 6 \mathrm{~mL}$ of TIOT was added into $34 \mathrm{~mL}$ of ethylic alcohol to make solution A. Solution B was prepared from $17 \mathrm{~mL}$ of ethanol, $0.4 \mathrm{~mL}$ of nitric acid $(68 \%), 1.6 \mathrm{~mL}$ distilled water, $48.2 \mathrm{mg}$ of $\mathrm{Fe}\left(\mathrm{NO}_{3}\right)_{3} .9 \mathrm{H}_{2} \mathrm{O}$, and $0.2 \mathrm{~g}$ of AC. The solution A was dropped into solution B under slow stir for 14 hours at room temperature and left for gelation for 2 days before being autoclaved in a Teflon vessel for 10 hours at $180^{\circ} \mathrm{C}$. The resulted powder was washed and dried at $100^{\circ} \mathrm{C}$ for 24 hours to obtain the $\mathrm{Fe}-\mathrm{C}-\mathrm{TiO}_{2} / \mathrm{AC}$ catalyst.
2.2. Characterization of As-Synthesized Photocatalyst. The crystal structure of catalyst was determined by XRD (D8Advance 5005). Transmission electron microscope (TEM, JEOL JEM-1010 electron Microscope) and high-resolution transmission electron microscopy (HR-TEM, Hitachi H-9000 NAR, Japan Advanced Institute of Science and Technology) were used to investigate the particle size and morphology of the samples. XPS spectra of the prepared samples were measured by an X-ray photoelectron spectroscopy (XPS) (Kratos Axis Ultra-Frederick Seitz Materials Research laboratory-University of Illinois, UrbanaChampaign, USA). The absorbance was conducted by UV-Vis spectroscopy (Tasco-V670 photospectrometer). Functional groups were identified by IR spectroscopy (IR prestige 21). Nitrogen isothermal adsorption (BrunauerEmmett-Teller (BET)) was determined by TriStar 3000 V6.07 A. Rhodamine B (RhB) concentrations were determined by a UV-Vis spectroscopy at the wavelength of $553 \mathrm{~nm}$ (the absorption maximum wavelength of $\mathrm{RhB}$ ).

\subsection{Photocatalytic Performance of As-Synthesized} Photocatalysts. The catalytic activity of prepared materials was examined by the degradation of RhB solution $(20 \mathrm{mg} / \mathrm{L})$ under visible-light irradiation. The compact light (36W) was used instead of solar light with a range of wavelengths from 400 to $700 \mathrm{~nm}$. An appropriate amount of catalyst (1-3 g/L) was added into $100 \mathrm{~mL}$ of $\mathrm{RhB}$ solution in a $250 \mathrm{~mL}$ beaker. The mixture was mixed at a constant rate in the dark for 30 minutes to ensure the desorption/adsorption equilibrium before being irradiated. After certain periods of time, the mixtures were sampled to determine the $\mathrm{RhB}$ concentrations by the UV-Vis spectroscopy.

\section{Results and Discussion}

3.1. Characterization of Synthesized Photocatalysts. Overall XPS spectra of principal elements Ti 2p, O 1s, C 1s, N 1s, and $\mathrm{Fe} 2 \mathrm{p}$ in synthesized photocatalysts are presented in Figure 1(a). The high-resolution scan over Ti 2p, O 1s, $\mathrm{C} 1 \mathrm{~s}, \mathrm{~N}$ 1s, and $\mathrm{Fe} 2 \mathrm{p}$ spectral regions is shown in Figures $1(\mathrm{~b})-1(\mathrm{f})$, respectively. The Ti $2 \mathrm{p}$ spectrum consists of peaks located at $459.1 \mathrm{eV}$ and $464.8 \mathrm{eV}$, indicating the existence of $\mathrm{Ti}$ (IV) in $\mathrm{TiO}_{2}$ component [1]. This suggests that the doping of iron and carbon then attached to the AC carrier does not alter the chemical state of $\mathrm{TiO}_{2}$. This result is consistent with the XRD results (Figure 2). O 1s spectrum consists of the main peak at $529.9 \mathrm{eV}$ and shoulder peak at $531.9 \mathrm{eV}$. These peaks correspond to Ti-O bond and $\mathrm{O}-\mathrm{H}$ groups in $\mathrm{TiO}_{2}$ [8]. This hydrogen hydroxyl group is useful for adsorption of organic substances or it can capture photogenic holes to form $\mathrm{HO}^{\bullet}$ free radicals that increase photocatalytic activity of photocatalysts.

The presence of peaks at $711.1 \mathrm{eV}$ and $723.1 \mathrm{eV}$ is attributed to $\mathrm{Fe}^{\mathrm{III}} 2 \mathrm{p}_{3 / 2}$ and $\mathrm{Fe}^{\mathrm{III}} 2 \mathrm{p}_{1 / 2}$; it is possible to predict the presence of iron in $\mathrm{Fe}^{3+}$ oxidation state. In addition, there is also the binding energy value at $709.2 \mathrm{eV}$ corresponding to $\mathrm{Fe}^{\mathrm{II}} 2 \mathrm{p}_{3 / 2}$, which characterizes the existence of $\mathrm{Fe}^{2+}$ ions, possibly in $\mathrm{FeO}[5]$. Coexistence of $\mathrm{Fe}^{3+}$ and $\mathrm{Fe}^{2+}$ 


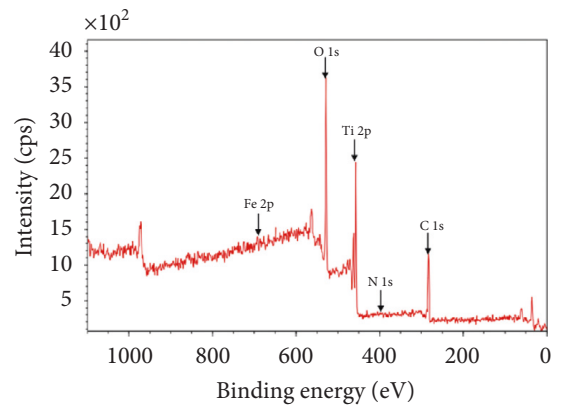

(a)

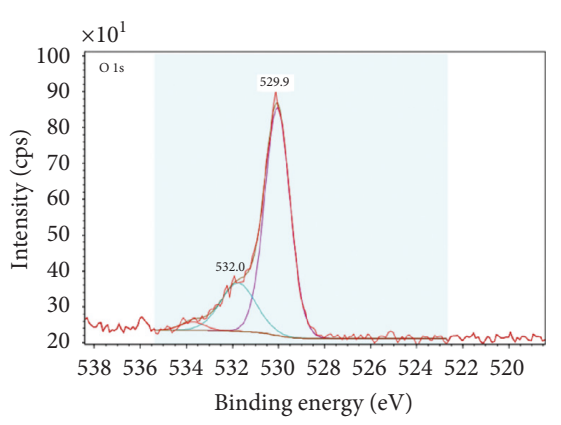

(c)

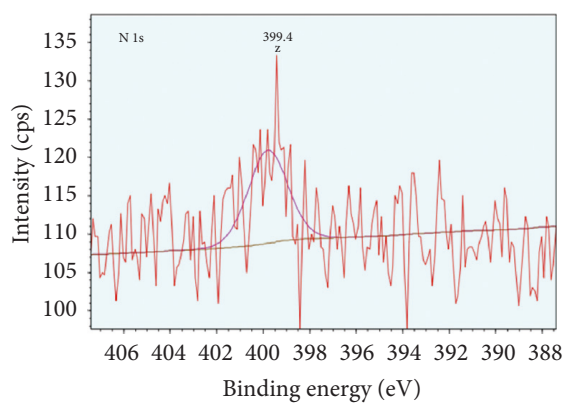

(e)

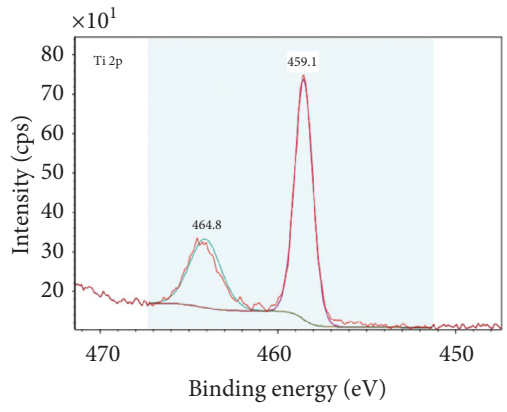

(b)

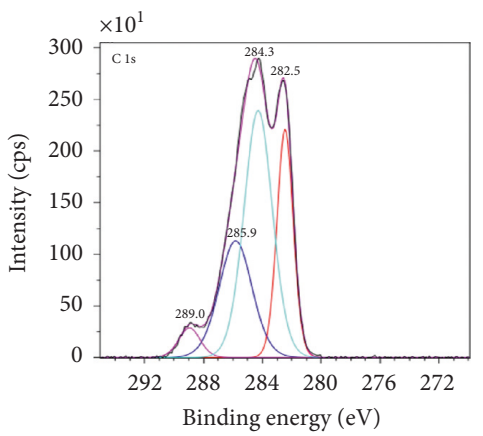

(d)

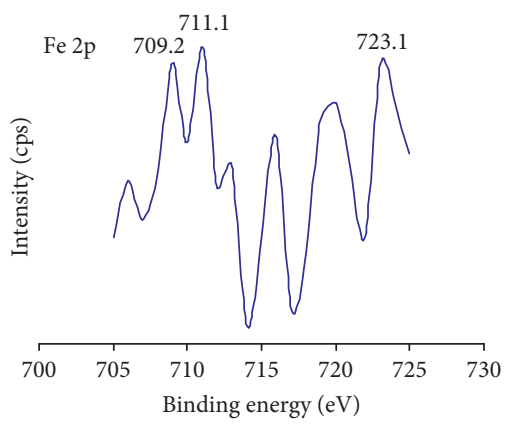

(f)

Figure 1: XPS spectra of Fe-C-TiO 2 /AC (a), Ti 2p (b), O 1s (c), C 1s (d), N 1s (e), and Fe 2p (f).

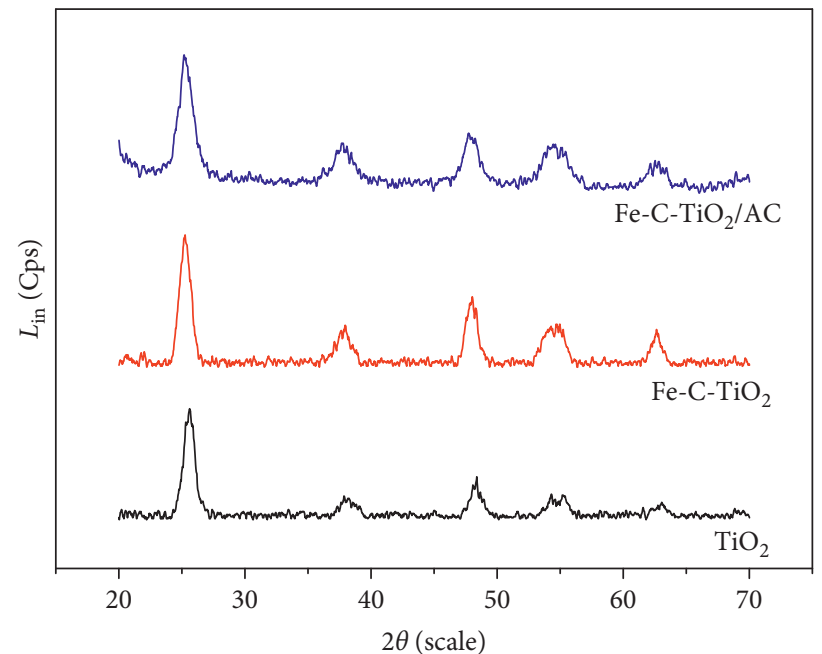

Figure 2: XRD patterns of $\mathrm{Fe}-\mathrm{C}-\mathrm{TiO}_{2} / \mathrm{AC}, \mathrm{Fe}-\mathrm{C}-\mathrm{TiO}_{2}$, and $\mathrm{TiO}_{2}$. 
can enhance the photocatalytic efficiency based on the following reactions:

$$
\begin{aligned}
\mathrm{Fe}^{2+}+\mathrm{O}_{\text {ads }} & \longrightarrow \mathrm{Fe}^{3+}+\mathrm{O}^{-}{ }_{\text {ads }} \\
\mathrm{Fe}^{3+}+\mathrm{e}^{-} \mathrm{CB} & \longrightarrow \mathrm{Fe}^{2+}
\end{aligned}
$$

in which $\mathrm{Fe}^{3+}$ acts as a conductive photonic electron trap to prevent recombination of electrons and holes, while $\mathrm{Fe}^{2+}$ provides electrons to adsorb oxygen on the catalytic surface and helps the charge transfer on the surface faster $[1,5]$.

Typical peaks of $\mathrm{C}$ are shown in Figure 1(d). The main peak with energy value at $284.3 \mathrm{eV}$ is assigned to carbon graphite. The presence of $285.9 \mathrm{eV}$ and $288.4 \mathrm{eV}$ peaks is associated with $\mathrm{C}-\mathrm{O}$ and $\mathrm{C}=\mathrm{O}$ bonds of catalytic surface carbonates [11]. The existence of this carbonate radical increases the sensitivity for catalysis, because of the involvement of carbon-containing functional groups in activated carbon [1]. A peak at $282.5 \mathrm{eV}$ corresponds to the Ti-C bond in the nanocrystalline catalyst attached to $\mathrm{AC}$, and this link proves that part of the carbon is involved in replacing the oxygen in the network $\mathrm{TiO}_{2}$ anatase crystals. The XPS analysis confirmed that iron and carbon had successfully entered the $\mathrm{TiO}_{2}$ network and also showed the successful binding of catalyst to activated carbon activated by $\mathrm{HNO}_{3}$.

The XRD patterns (Figure 2) show that $\mathrm{Fe}-\mathrm{C}-\mathrm{TiO}_{2}$ after being coated on activated carbon exhibits the typical peaks referring to the anatase form [6]. The phase composition of nanoscale particles is preserved compared with the original materials (Figure 3).

The TEM images of the $\mathrm{Fe}-\mathrm{C}-\mathrm{TiO}_{2} / \mathrm{AC}$ sample (Figure 3(a)) show that the catalyst system contains very fine particles, with typical size of $5 \mathrm{~nm}$, evenly distributed on the surface of activated carbon. The result of HR-TEM (Figure 3(b)) confirms the $\mathrm{Fe}-\mathrm{C}-\mathrm{TiO}_{2}$ catalyst binding on $\mathrm{AC}$ is based on black spots covered by catalytic spheres [10].

Proposed mechanism of $\mathrm{TiO}_{2}$ coating process on $\mathrm{AC}$ is shown in Figure 4. After AC was pretreated with $\mathrm{HNO}_{3}$, carbon supplied more hydroxyl and acid groups on the surface, which bond to $\mathrm{OH}^{-}$and $\mathrm{H}^{+}$ions of catalyst to enhance the adhesiveness.

Table 1 shows that the surface areas of pristine AC and $\mathrm{AC}$ carrying catalysts measured by BET are different. The reason is that during the treatment of $\mathrm{AC}, \mathrm{HNO}_{3}$ is a strong oxidant, leading to changes in porous structure, which might reduce the number of small capillaries and increase the number of large ones, therefore reducing the surface area.

IR spectra of pristine $\mathrm{TiO}_{2}, \mathrm{Fe}-\mathrm{C}-\mathrm{TiO}_{2}$, and $\mathrm{Fe}-\mathrm{C}-\mathrm{TiO}_{2} /$ $\mathrm{AC}$ are presented in Figure 5. Peak at $1436 \mathrm{~cm}^{-1}$ refers to the -COO-Ti vibration. The peaks at $551 \mathrm{~cm}^{-1}$ and $502-505 \mathrm{~cm}^{-1}$ are assigned to the bonds of $\mathrm{Ti}-\mathrm{O}$ and $\mathrm{Ti}-\mathrm{O}-\mathrm{C}$, respectively.

The UV-Vis spectra of the samples are displayed in Figure 6. The results show that by coating $\mathrm{Fe}-\mathrm{C}-\mathrm{TiO}_{2}$ on $\mathrm{AC}$, the absorption band of $\mathrm{Fe}-\mathrm{C}-\mathrm{TiO}_{2} / \mathrm{AC}$ was significantly expanded to the visible region in comparison with the absorption band of pristine $\mathrm{TiO}_{2}$ and $\mathrm{Fe}-\mathrm{C}-\mathrm{TiO}_{2}$. Indeed, as expected, the main absorption edge of $\mathrm{TiO}_{2}$ was estimated to be about $398 \mathrm{~nm}(2.96 \mathrm{eV})$ due to its intrinsic band gap absorption. The onset of the absorption spectrum of Fe-C-
$\mathrm{TiO}_{2}$ was shifted to the visible region because of the $\mathrm{Fe}$ and $\mathrm{C}$ dopants while $\mathrm{Fe}-\mathrm{C}-\mathrm{TiO}_{2} / \mathrm{AC}$ presented main absorption spectrum at the region above $480 \mathrm{~nm}$. This result suggests that the $\mathrm{Fe}-\mathrm{C}-\mathrm{TiO}_{2} / \mathrm{AC}$ catalyst is more active under visible light.

From the UV-Vis spectra of pristine $\mathrm{TiO}_{2}, \mathrm{Fe}-\mathrm{C}-\mathrm{TiO}_{2}$, and $\mathrm{Fe}-\mathrm{C}-\mathrm{TiO}_{2} / \mathrm{AC}$ (Figure 7), the band gap energies estimated from the intercept of the tangents to the plots by using Kubelka-Munk method were 2.96, 2.17, and $1.63 \mathrm{eV}$ for pristine $\mathrm{TiO}_{2}, \mathrm{Fe}-\mathrm{C}-\mathrm{TiO}_{2}$, and $\mathrm{Fe}-\mathrm{C}-\mathrm{TiO}_{2} / \mathrm{AC}$, respectively.

3.2. Catalytic Activity of $\mathrm{Fe}-\mathrm{C}-\mathrm{TiO}_{2} / \mathrm{AC}$ in the Degradation of RhB under Visible Light. The comparison of photocatalytic performance of $\mathrm{Fe}-\mathrm{C}-\mathrm{TiO}_{2} / \mathrm{AC}, \mathrm{Fe}-\mathrm{C}-\mathrm{TiO}_{2}$, and $\mathrm{TiO}_{2}$ with that of pure $\mathrm{AC}$ in the degradation of $\mathrm{RhB}$ under visible-light irradiation with the same catalyst load $(1.6 \mathrm{~g} / \mathrm{L})$ is presented in Figure 8. AC adsorbs $\mathrm{RhB}$ and reaches the equilibrium after $60 \mathrm{~min}$ of reaction, which can be proved by unchanged $\mathrm{RhB}$ concentration over time. The results also indicate that $\mathrm{Fe}-\mathrm{C}-\mathrm{TiO}_{2} / \mathrm{AC}$ is the best photocatalyst in degradation of $\mathrm{RhB}$ in solutions with more than $99 \%$ of $\mathrm{RhB}$ removal after 90 min while pristine $\mathrm{TiO}_{2}$ exhibits the lowest performance (only some $40 \%$ of $\mathrm{RhB}$ is removed after the same reaction time). Pure $\mathrm{AC}$ and $\mathrm{Fe}-\mathrm{C}-\mathrm{TiO}_{2}$ present photocatalytic efficiency in between pristine $\mathrm{TiO}_{2}$ and $\mathrm{Fe}-\mathrm{C}-\mathrm{TiO}_{2} / \mathrm{AC}$. This illustrates the synergy between adsorption capacity of $\mathrm{AC}$ and the improvement of $\mathrm{Fe}-\mathrm{C}-\mathrm{TiO}_{2}$ compared with pristine $\mathrm{TiO}_{2}$.

Figure 9 shows that the optimal catalyst load was $1.6 \mathrm{mg} / \mathrm{L}$ in the degradation of $\mathrm{RhB}$ in solutions while more dilute or concentrated catalyst concentrations will result in lower levels of RhB degradation. In fact, more than $99 \%$ of $\mathrm{RhB}$ was decomposed after $90 \mathrm{~min}$ of visible-light irradiation with a catalyst load of $1.6 \mathrm{mg} / \mathrm{L}$ while these figures for the catalyst loads at $1,1.2,1.4,1.8$, and 2.5 were, respectively, $40 \%, 50 \%, 53 \%, 78 \%$, and $62 \%$. This can be explained by the fact that the higher quantity of catalyst load may cause the light absorption hindrance, decreasing the efficiency of RhB degradation, whereas the lower catalyst load would lead to lower active sites ready for the degradation of the pollutant.

The photocatalytic degradation of $\mathrm{RhB}$ by the Fe-C$\mathrm{TiO}_{2} / \mathrm{AC}$ system can be explained by the following mechanism proposal (Figure 10): (1) when $h v \geq\left(E_{C}-E_{V}\right)$, then electrons would be excited in the valence band of $\mathrm{TiO}_{2}$ by the process: $\mathrm{TiO}_{2}+\mathrm{h} v(\mathrm{UV}) \longrightarrow \mathrm{TiO}_{2}\left(\mathrm{e}_{\mathrm{CB}}-+\mathrm{h}_{\mathrm{VB}}+\right)$; (2) when $\left(\mathrm{E}_{\mathrm{C}}-\mathrm{E}_{\mathrm{V}}^{\prime}\right) \leq \mathrm{h} v<\left(\mathrm{E}_{\mathrm{C}}-\mathrm{E}_{\mathrm{V}}\right)$, electrons can be excited from the $\mathrm{Fe}-\mathrm{C}-\mathrm{TiO}_{2} / \mathrm{AC}$ energy level by the following process: $\mathrm{Fe}-\mathrm{C}-$ $\mathrm{TiO}_{2} / \mathrm{C}+\mathrm{h} v$ (visible) $\longrightarrow \mathrm{Fe}-\mathrm{C}-\mathrm{TiO}_{2} / \mathrm{AC}\left(\mathrm{e}_{\mathrm{CB}}-+\mathrm{h}_{\mathrm{VB}}+\right)$; and (3) when $\left(\mathrm{E}_{\mathrm{V}}{ }-\mathrm{E}_{\mathrm{V}}\right) \leq \mathrm{h}<\left(\mathrm{E}_{\mathrm{C}}-\mathrm{E}_{\mathrm{W}}\right)$, electrons would be excited and moved from the valence band of $\mathrm{TiO}_{2}$ to the $\mathrm{Fe}$ $\mathrm{C}-\mathrm{TiO}_{2} / \mathrm{AC}$ energy level by the process: $\mathrm{TiO}_{2}+\mathrm{Fe}-\mathrm{C}-\mathrm{TiO}_{2} /$ $\mathrm{C}+\mathrm{h} v \quad$ (visible) $\longrightarrow \mathrm{Fe}-\mathrm{C}-\mathrm{TiO}_{2} / \mathrm{AC} \quad\left(\mathrm{e}_{\mathrm{CB}}-\right)+\mathrm{TiO}_{2} \quad\left(\mathrm{~h}_{\mathrm{VB}}+\right)$. The departed electrons and holes subsequently migrate to the surface of the catalysts and react with adsorbed $\mathrm{H}_{2} \mathrm{O}$ and $\mathrm{O}_{2}$ molecules, forming $\mathrm{HO}^{\circ}$ and $\mathrm{O}_{2}$, respectively. $\mathrm{HO}^{\circ}$ and $\mathrm{O}_{2}$ radicals are mainly responsible for the degradation of $\mathrm{RhB}$ in solution [12]. 


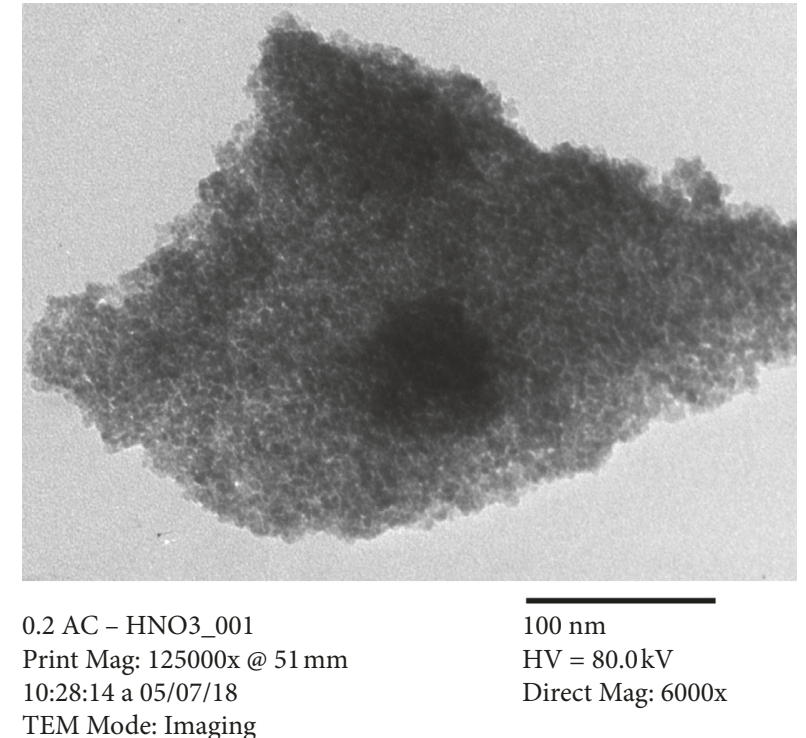

(a)

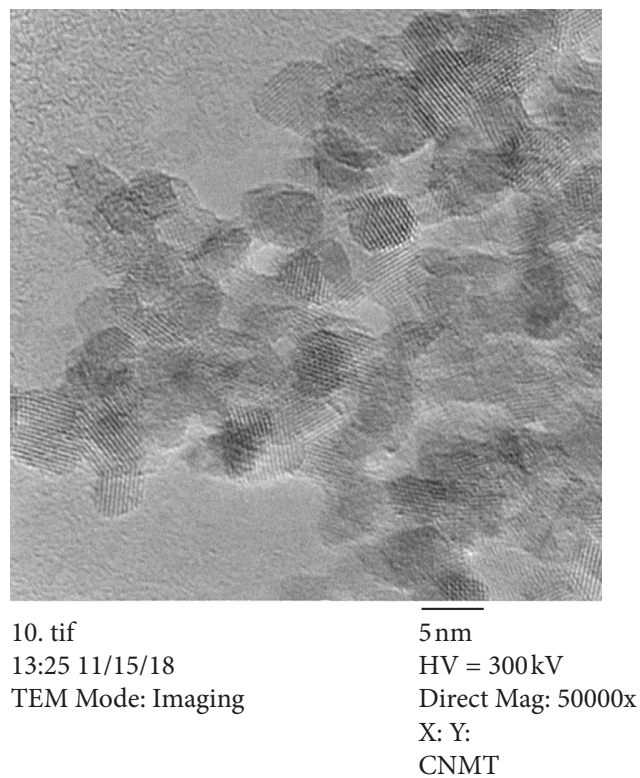

(b)

Figure 3: TEM images of Fe-C- $\mathrm{TiO}_{2} / \mathrm{AC}$ (a) and HR-TEM of $\mathrm{Fe}-\mathrm{C}-\mathrm{TiO}_{2} / \mathrm{AC}(\mathrm{b})$.

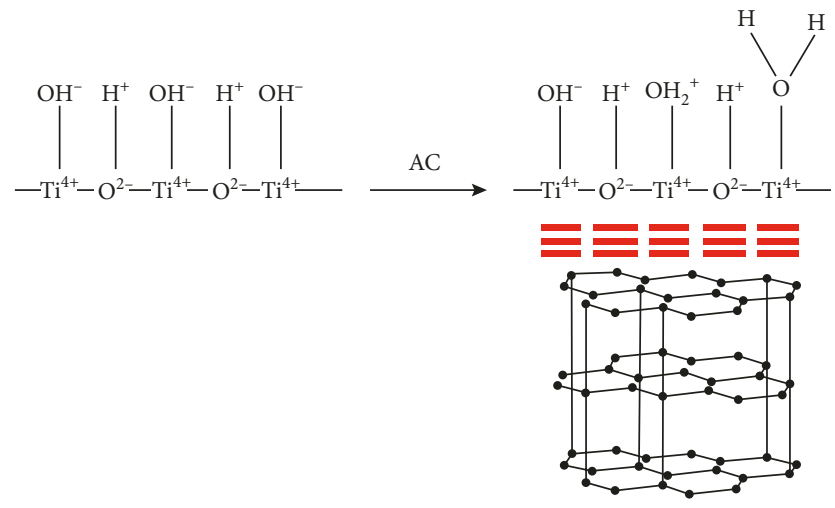

Figure 4: Proposed mechanism of $\mathrm{TiO}_{2}$ coating process on AC.

TABLE 1: Physical properties of AC, Fe-C-TiO 2 , and $\mathrm{Fe}-\mathrm{C}-\mathrm{TiO}_{2} / \mathrm{AC}$.

\begin{tabular}{lccc}
\hline Materials & $\begin{array}{c}\text { Mean size (nm) from the } \\
\text { XRD results }\end{array}$ & $\begin{array}{c}\text { BET surface } \\
\text { area }\left(\mathrm{m}^{2} \cdot \mathrm{g}^{-1}\right)\end{array}$ & $\begin{array}{c}V_{\mathrm{p}} \\
\left(\mathrm{cm}^{3} \cdot \mathrm{g}^{-1}\right)\end{array}$ \\
\hline $\begin{array}{l}\mathrm{Fe}-\mathrm{C}- \\
\mathrm{TiO}\end{array} \mathrm{AC}_{2} / \mathrm{AC}$ & 5.13 & 264.8 & 0.30 \\
$\mathrm{Fe}-\mathrm{C}-$ & 4.23 & 237.2 & 0.23 \\
$\mathrm{TiO}_{2}$ & - & 928.2 & - \\
$\mathrm{AC}$ & & & \\
\hline
\end{tabular}

The catalytic stability in RhB decomposition under visiblelight irradiation was studied. After each decomposition cycle (90 min), the catalyst was centrifuged and washed with distilled water and then used for further treatment of $\mathrm{RhB}$ in solution. The results show that the catalyst exhibited good photocatalytic activity after 5 cycles, as shown in Figure 11 . The ability to decompose RhB over 5 cycles remained high (>87\%). This research has proved that $\mathrm{Fe}-\mathrm{C}-\mathrm{TiO}_{2} / \mathrm{AC}$ is a highly durable, economically suitable, and practical catalyst.

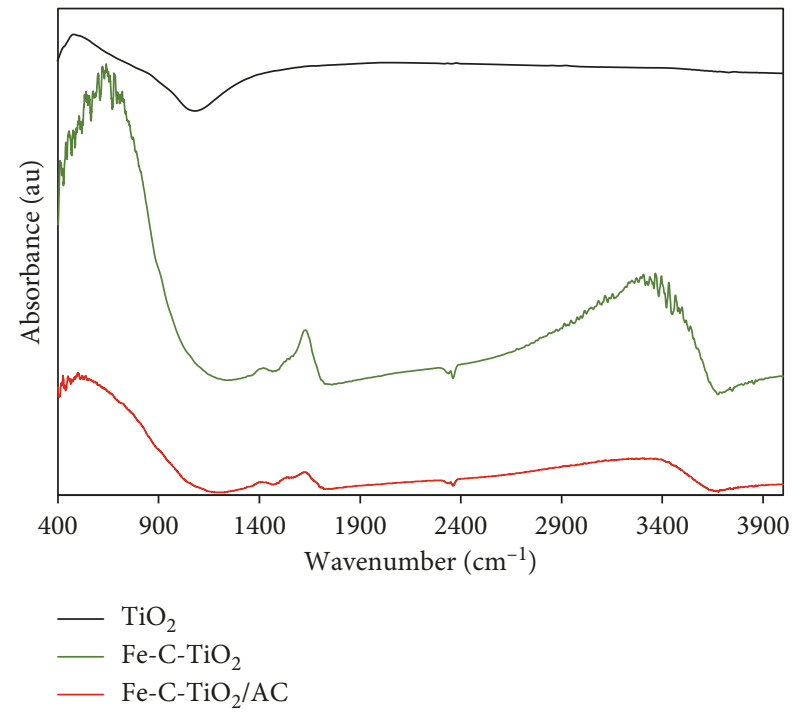

Figure 5: IR spectra of Fe-C- $\mathrm{TiO}_{2} / \mathrm{AC}, \mathrm{Fe}-\mathrm{C}-\mathrm{TiO}_{2}$, and $\mathrm{TiO}_{2}$.

\section{Conclusions}

The $\mathrm{Fe}-\mathrm{C}-\mathrm{TiO}_{2}$ catalyst was successfully carried on the AC treated by $\mathrm{HNO}_{3}$. The nature of the catalyst remained to be unchanged regarding phase composition, particle sizes, and structure. Furthermore, the large surface area of AC adsorbs more organic molecules, leading to enhance the RhB degradation in solutions. The catalyst after being deposited on AC carriers activated with $\mathrm{HNO}_{3}$ has better photocatalytic activity than activated carbon without catalysts. The $\mathrm{Fe}-\mathrm{C}$ $\mathrm{TiO}_{2} / \mathrm{AC}$ catalyst also presented better photocatalytic performance in $\mathrm{RhB}$ degradation compared with pristine $\mathrm{TiO}_{2}$ and with $\mathrm{Fe}-\mathrm{C}-\mathrm{TiO}_{2}$. The optimal catalyst load for $\mathrm{RhB}$ 


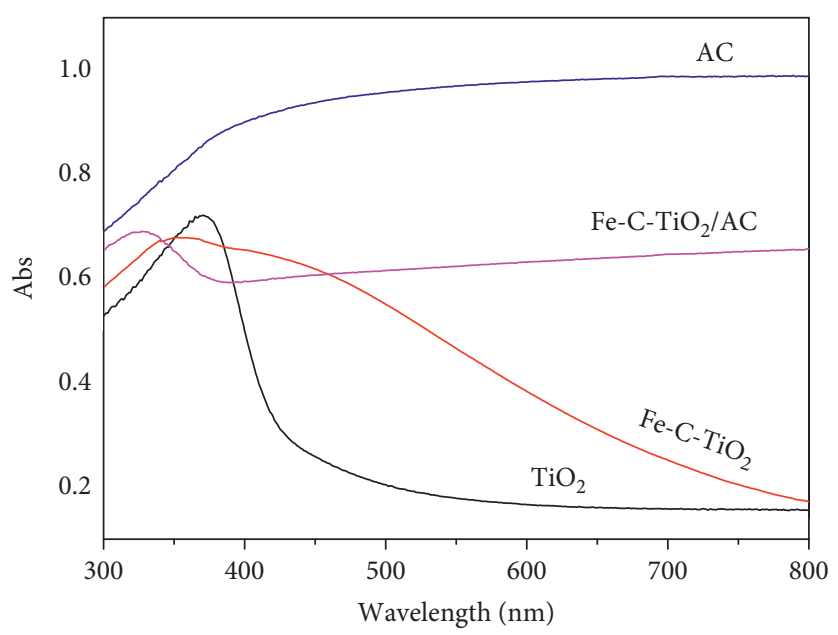

Figure 6: UV-Vis spectra of pure AC, Fe-C- $\mathrm{TiO}_{2} / \mathrm{AC}, \mathrm{Fe}-\mathrm{C}-\mathrm{TiO}_{2}$, and $\mathrm{TiO}_{2}$.

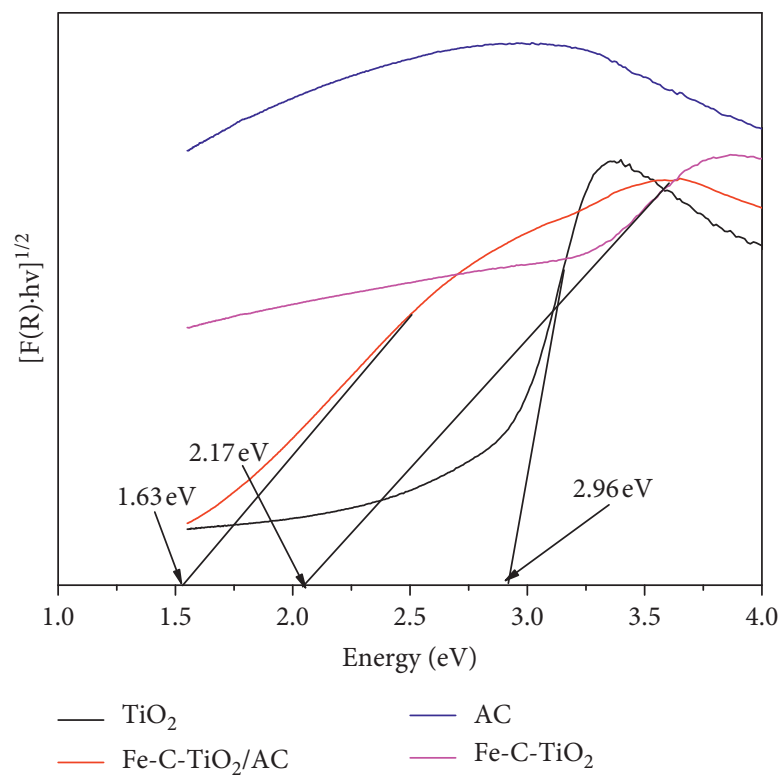

Figure 7: Plot of $[\mathrm{F}(\mathrm{R}) \cdot \mathrm{h} v]^{1 / 2}$ vs energy $(\mathrm{eV})$ for pure $\mathrm{AC}, \mathrm{Fe}-\mathrm{C}-\mathrm{TiO}_{2} / \mathrm{AC}, \mathrm{Fe}-\mathrm{C}-\mathrm{TiO}_{2}$, and $\mathrm{TiO}_{2}$.

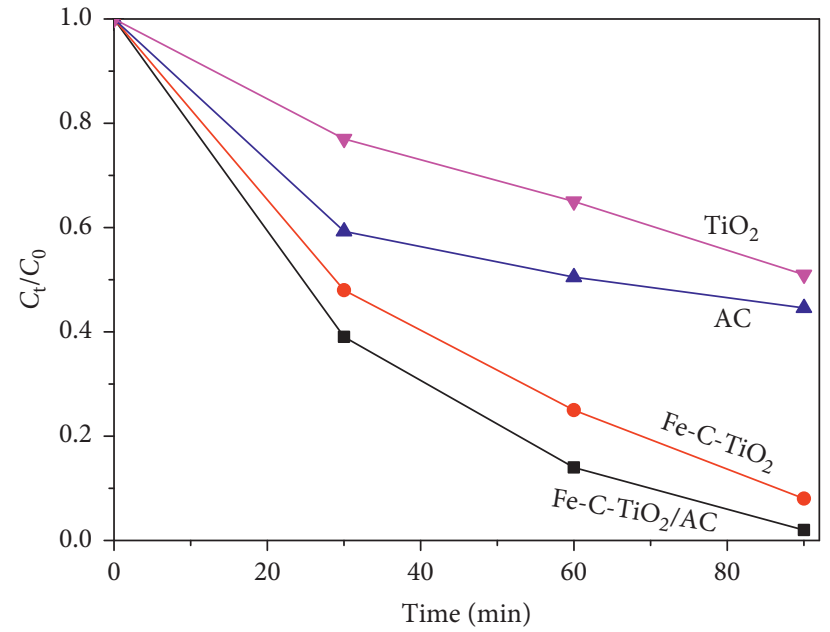

Figure 8: Comparison of photocatalytic activity of $\mathrm{Fe}-\mathrm{C}-\mathrm{TiO}_{2} / \mathrm{AC}, \mathrm{Fe}-\mathrm{C}-\mathrm{TiO}_{2}$, and $\mathrm{TiO}_{2}$ with that of pure AC. 


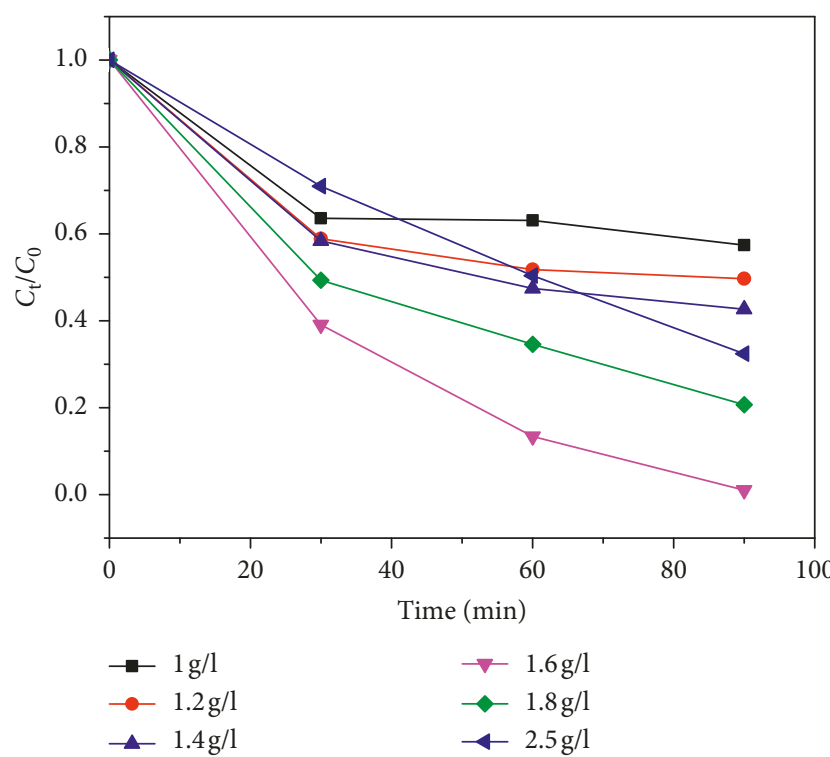

Figure 9: Optimization of catalyst load in the degradation of $\mathrm{RhB}$ by $\mathrm{Fe}-\mathrm{C}-\mathrm{TiO}_{2} / \mathrm{AC}$.

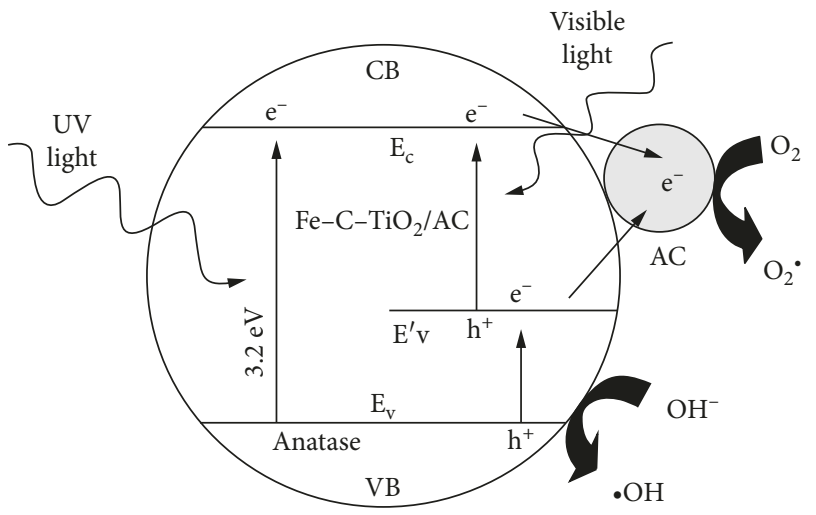

FIgURE 10: Schematic mechanism of photocatalytic degradation of $\mathrm{RhB}$ by $\mathrm{Fe}-\mathrm{C}-\mathrm{TiO}_{2} / \mathrm{AC}$ (adopted from [12]).

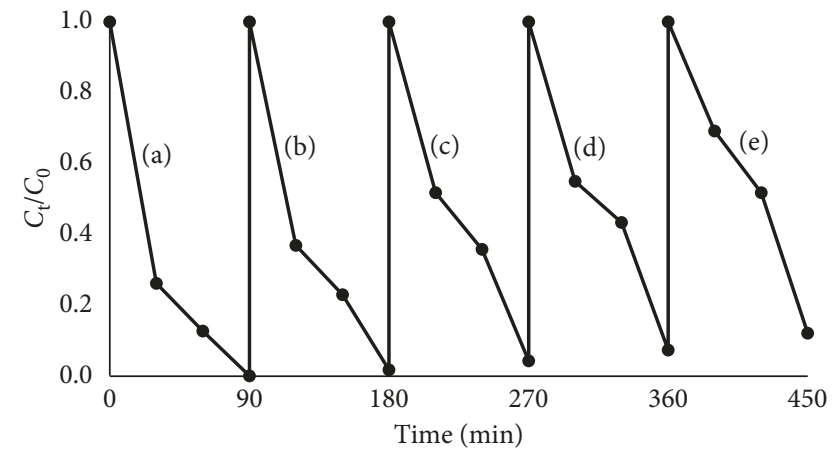

Figure 11: Photocatalytic recycling of $\mathrm{Fe}-\mathrm{C}-\mathrm{TiO}_{2} / \mathrm{AC}$ in $\mathrm{RhB}$ decomposition: first cycle (a); second cycle (b); third cycle (c); fourth cycle (d); fifth cycle (e).

decomposition (initial concentration of $20 \mathrm{mg} / \mathrm{L}$ ) was found to be of $1.6 \mathrm{~g} / \mathrm{L}$. The catalysts with larger size favor the catalyst separation from solution and recycling. The Fe-C-
$\mathrm{TiO}_{2}$ carried on AC sample is a potential catalyst in degradation of toxic organic compounds under visible-light irradiation.

\section{Data Availability}

The data used to support the findings of this study are included within the article.

\section{Conflicts of Interest}

The authors declare that there are no conflicts of interest regarding the publication of this paper.

\section{Acknowledgments}

This work was partly supported by the team project of VLIRUOS with code number ZEIN2016PR431. The authors would like to thank the RoHan project for the utilization of instruments.

\section{References}

[1] X. Wang, Y. Tang, M.-Y. Leiw, and T.-T. Lim, "Solvothermal synthesis of $\mathrm{Fe}-\mathrm{C}$ codoped $\mathrm{TiO}_{2}$ nanoparticles for visible-light photocatalytic removal of emerging organic contaminants in water," Applied Catalysis A: General, vol. 409-410, pp. 257266, 2011.

[2] S. Jafari, B. Tryba, E. Kusiak-Nejman, J. Kapica-Kozar, A. W. Morawski, and M. Sillanpää, "The role of adsorption in the photocatalytic decomposition of Orange II on carbonmodified $\mathrm{TiO}_{2}$," Journal of Molecular Liquids, vol. 220, pp. 504-512, 2016.

[3] Y. Wu, J. Zhang, L. Xiao, and F. Chen, "Properties of carbon and iron modified $\mathrm{TiO}_{2}$ photocatalyst synthesized at low temperature and photodegradation of acid orange 7 under visible light," Applied Surface Science, vol. 256, pp. 260-268, 2010.

[4] Z. Hu, T. Xu, and B. Fang, "Photocatalytic degradation of vehicle exhaust using $\mathrm{Fe}$-doped $\mathrm{TiO}_{2}$ loaded on activated carbon," Applied Surface Science, vol. 420, pp. 34-42, 2017.

[5] Y. Li, J. Chen, J. M. Liu, M. Ma, W. Chen, and L. Li, "Activated carbon supported $\mathrm{TiO}_{2}$-photocatalysis doped with $\mathrm{Fe}$ ions for continuous treatment of dye wastewater in a dynamic reactor," Journal of Environmental Sciences, vol. 22, no. 8, pp. 1290-1296, 2010.

[6] A. Eshaghi and H. Moradi, "Optical and photocatalytic properties of the Fe-doped $\mathrm{TiO}_{2}$ nanoparticles loaded on the activated carbon," Advanced Powder Technology, vol. 29, no. 8, pp. 1879-1885, 2018.

[7] N. C. Birben, C. S. Uyguner-Demirel, S. S. Kavurmaci et al., "Application of Fe-doped $\mathrm{TiO}_{2}$ specimens for the solar photocatalytic degradation of humic acid," Catalysis Today, vol. 281, no. 1, pp. 78-84, 2017.

[8] P.-S. Yap and T.-T. Lim, "Effect of aqueous matrix species on synergistic removal of bisphenol-A under solar irradiation using nitrogen-doped $\mathrm{TiO}_{2} / \mathrm{AC}$ composite," Applied Catalysis B: Environmental, vol. 101, no. 3-4, pp. 709-717, 2011.

[9] Z. F. Shi, S. M. Zhang, and S. Guo, "Characteristics and photocatalytic activity of TiO," Applied Mechanics and Materials, vol. 295-298, pp. 413-417, 2013. 
[10] D. Huang, Y. Miyamoto, J. Ding et al., "A new method to prepare high-surface-area $\mathrm{N}-\mathrm{TiO}_{2}$ /activated carbon," Materials Letters, vol. 65, pp. 326-328, 2011.

[11] X. Cheng, X. Yu, and Z. Xing, "Synthesis and characterization of C-N-S-tridoped $\mathrm{TiO}_{2}$ nano-crystalline photocatalyst and its photocatalytic activity for degradation of rhodamine B," Journal of Physics and Chemistry of Solids, vol. 74, pp. 684690, 2013.

[12] L. Youji, Z. Xiaoming, C. Wei et al., "Photodecolorization of Rhodamine $\mathrm{B}$ on tungsten-doped $\mathrm{TiO}_{2}$ /activated carbon under visible-light irradiation," Journal of Hazardous Materials, vol. 227, no. 228, pp. 25-33, 2012. 

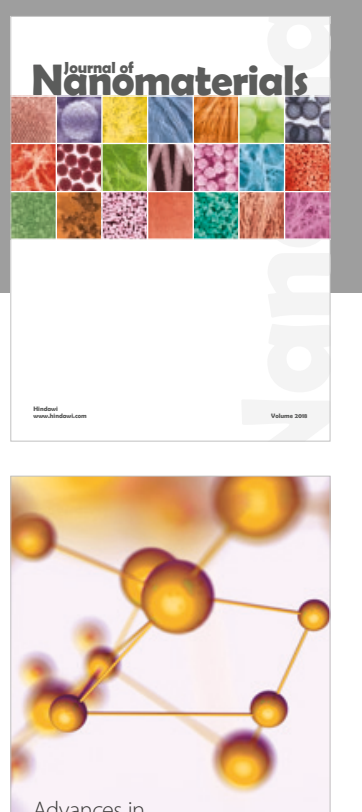

Physical Chemistry
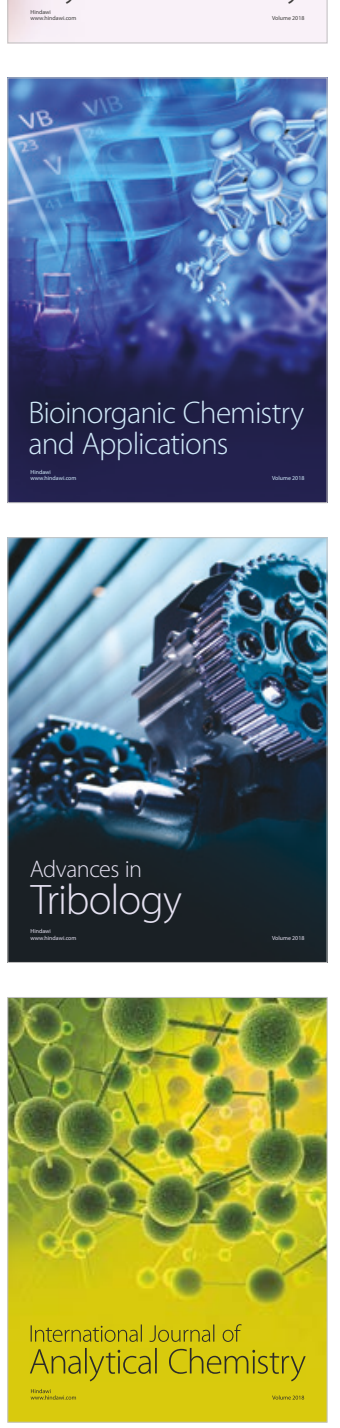

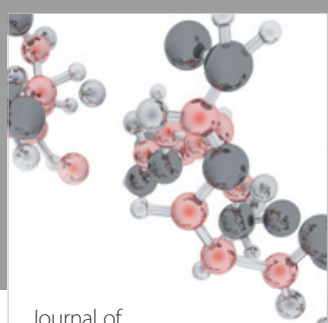

Analytical Methods

in Chemistry

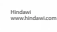

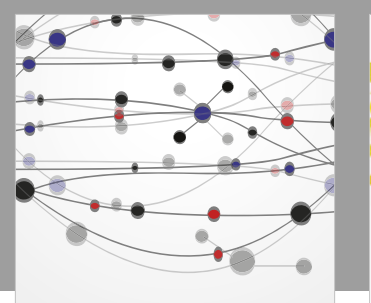

The Scientific World Journal

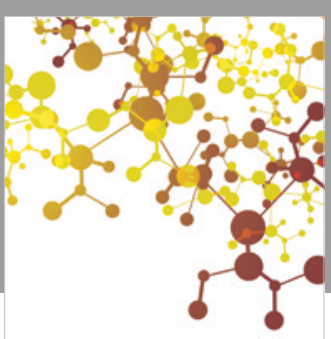

Journal of

Applied Chemistry
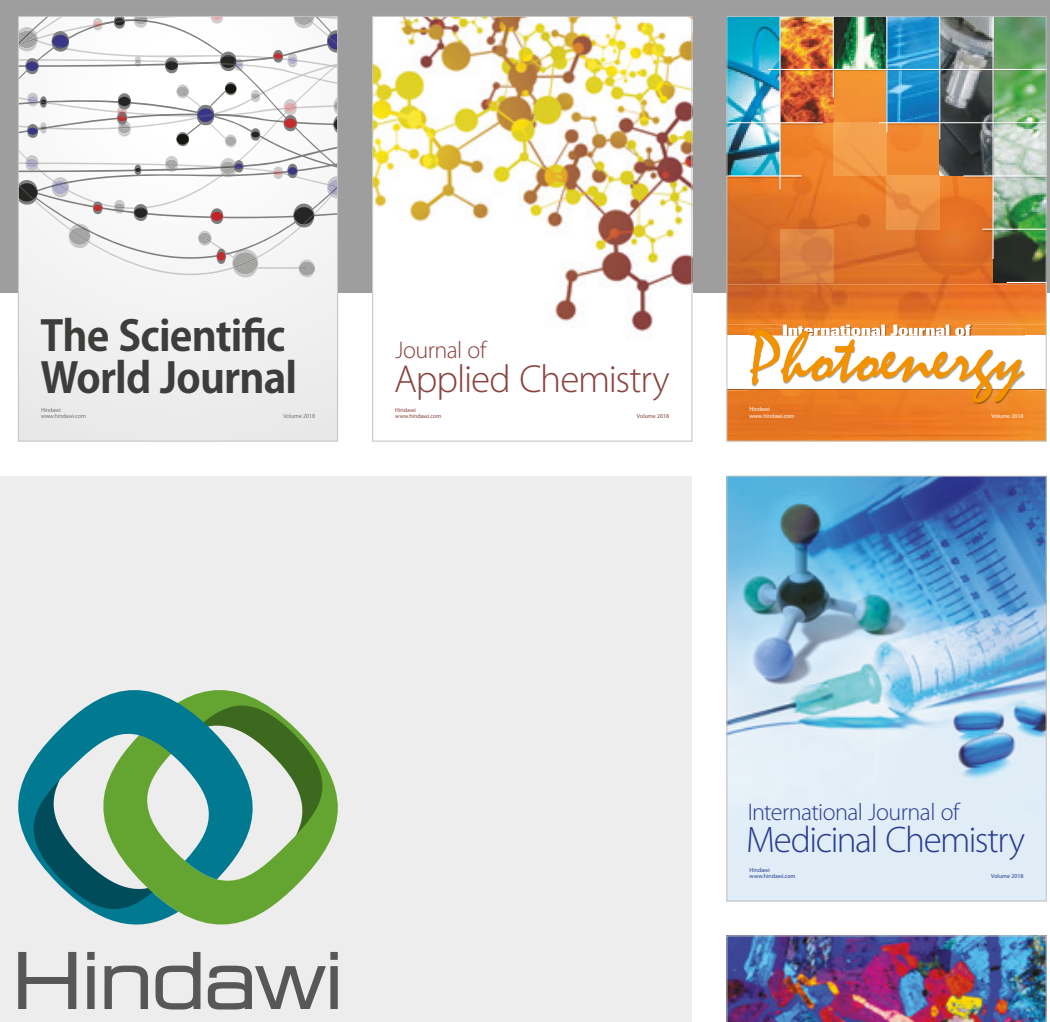

Submit your manuscripts at

www.hindawi.com
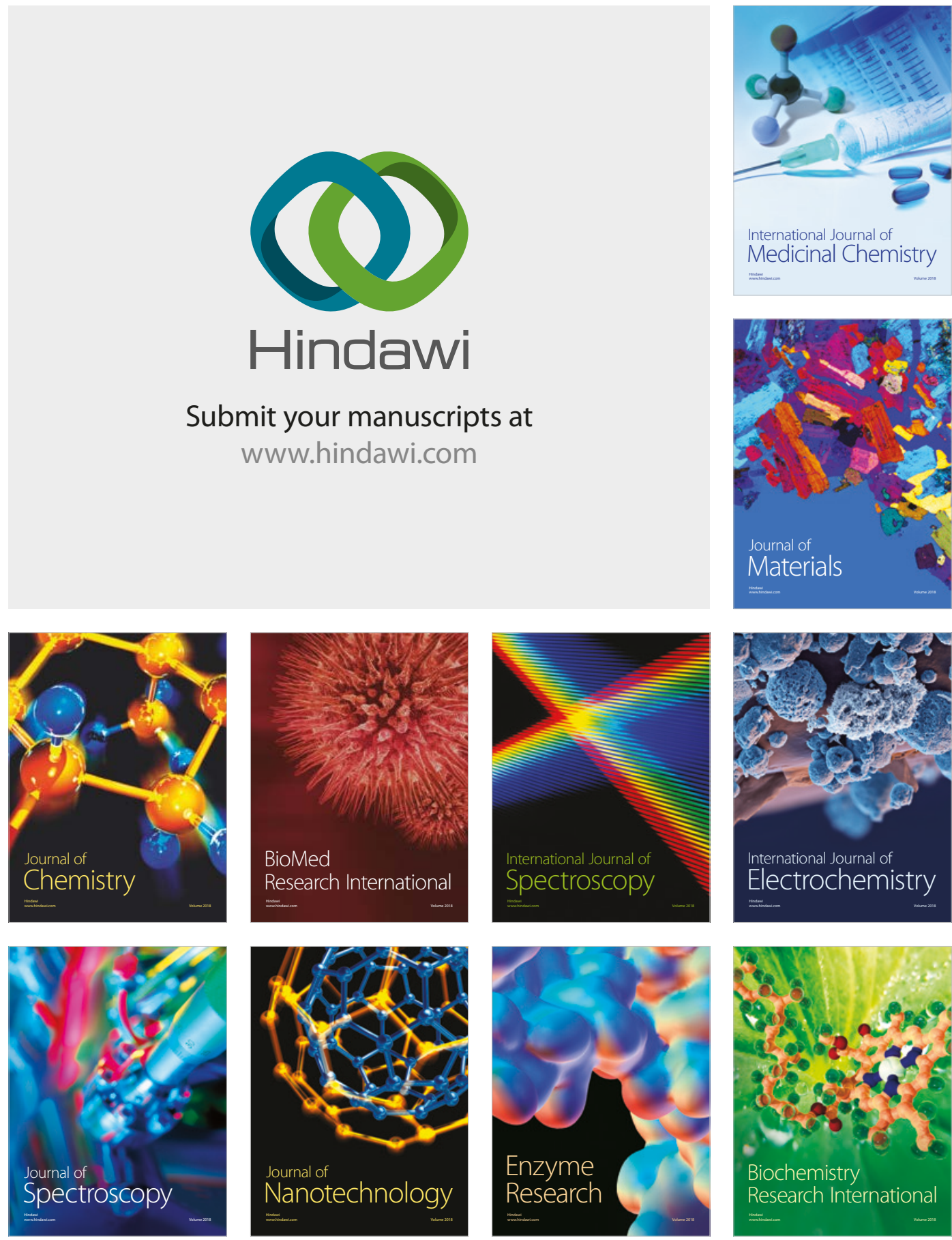
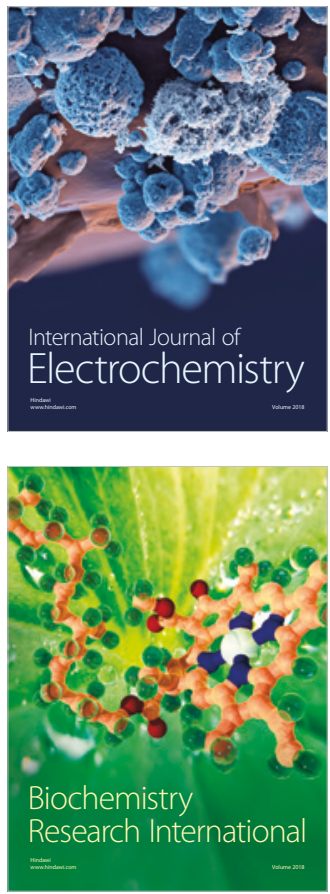